\title{
Decreased frequency of adenoidectomy by a I2-week nasal budesonide treatment
}

\author{
This article was published in the following Dove Press journal: \\ Therapeutics and Clinical Risk Management \\ 3 October 2017 \\ Number of times this article has been viewed
}

\author{
Haiyu Hong ${ }^{1, *}$ \\ Fenghong Chen ${ }^{2, *}$ \\ Xiaobin Zheng ${ }^{3}$ \\ Wei Liao' \\ Zhenpeng Liao' \\ Yujie $\mathrm{CaO}^{2}$ \\ Haixin $\mathrm{He}^{1}$ \\ Zhe Zhu ${ }^{4,5}$ \\ Yunping Fan'
}

'Department of Otolaryngology and Head Neck Surgery of 5th

Hospital, Affiliated with Sun Yat-sen University, Zhuhai, ${ }^{2}$ Department of Otolaryngology and Head Neck Surgery of Ist Hospital, Affiliated with Sun Yat-sen University, Guangzhou, ${ }^{3}$ Department of Respiration of 5th Hospital, Affiliated with Sun Yat-sen University, Zhuhai, China; ${ }^{4}$ Department of Stem Cell Biology and Regenerative Medicine, Lerner Research Institute, Cleveland Clinic, Cleveland, $\mathrm{OH},{ }^{5}$ Sanford Consortium, Regenerative Medicine, University of California, San Diego, La Jolla, CA, USA

*These authors contributed equally to this work

Correspondence: Yunping Fan Department of Otolaryngology and Head Neck Surgery of 5th Hospital, Affiliated with Sun Yat-sen University, No 52 Meihua east road, Xiangzhou, Zhuhai 519020, China

Email zhfyp8835@I63.com
Objective: There is little evidence on the role of topical budesonide in reducing the frequency of adenoidectomy, although it was reported that topical budesonide can effectively ameliorate the symptoms of adenoid hypertrophy (AH). This study was aimed to investigate the possibility and safety of alternatives to adenoidectomy with a 12-week treatment with nasal budesonide. Materials and methods: One hundred patients with $\mathrm{AH}$ were randomized to receive either a double-blind budesonide ( $1 \mathrm{mg}$ once daily) or placebo treatment for 2 weeks by transnasal nebulization. A further 12-week open study, budesonide spray (64 $\mu \mathrm{g}$ per nostril at bedtime) was administered to the treatment group. During the final 12 weeks of follow-up, the frequency of adenotonsillectomy, side effects, the degree of nasal obstruction, nasal discharge, and snoring were assessed.

Results: Out of the 100 total enrolled patients, 92 children with AH completed the study. After the 2-week treatment with transnasal budesonide nebulization, the symptoms of AH significantly decreased compared to the control group. Responders $(n=26)$ who had initially improved showed significantly decreased symptoms of $\mathrm{AH}$, and the frequency of adenotonsillectomy during the follow-up (14 and 26 weeks) was compared with that of the control group and non-responders $(n=21)$ who did not respond to the initial 2-week budesonide therapy. The 12-week nasal budesonide treatment did not suppress the growth rate of children's height or cause other side effects.

Conclusion: AH children who had improved after an initial 2-week budesonide therapy can achieve clinical improvements and decreased frequency of adenoidectomy following the therapy with a 12-week treatment with nasal budesonide.

Keywords: adenoid hypertrophy, adenoidectomy, budesonide, frequency, treatment

\section{Introduction}

Adenoid hypertrophy (AH), which obstructs the nasal airway in patients, is associated with multiple symptoms including snoring, nasal discharge, nasal congestion, chronic mouth breathing, halitosis, hyponasal speech, restless sleep, hypersomnolence, and enuresis. ${ }^{1-3} \mathrm{AH}$ is the most common cause of obstructive sleep apnea (OSA) in children. It also plays a major role in chronic rhinosinusitis and otitis media with effusion (OME) ${ }^{4,5}$ Adenoidectomy has been the definitive treatment for relief from upper airway obstruction and diseases complicated by or attributable to AH. ${ }^{2,46}$

Although adenoidectomy may be the final option for some children with $\mathrm{AH}$, the operation under general anesthesia should be balanced against the risks carefully, including the risk of side effects. ${ }^{1}$ A medical alternative for safe and sustained relief from adenoidal upper airway obstruction may be available. Some studies ${ }^{7,8}$ have demonstrated that properly administered daily nasal beclomethasone may reduce adenoid size enough to relieve the symptoms of AH for several weeks to months, but other studies have not corroborated this finding. ${ }^{9}$ 
Budesonide nasal spray has been used to treat allergic rhinitis and nasal polyps for decades. Clinical trials have proved that it is a safe and effective anti-inflammatory agent. ${ }^{10-13}$ Some studies had found that budesonide could suppress lymphoid tissue proliferation in vitro in children with OSA, and a 6-week treatment with intranasal budesonide effectively reduced the severity of OSA. ${ }^{14,15}$ However, whether long-term treatment with nasal budesonide could impair growth in children and reduce the frequency of surgery among children with AH remains unknown.

Thus, the aim of this study was to investigate the clinical efficacy and safety of a 12-week course of nasal budesonide administration to children with $\mathrm{AH}$. In addition, the study aimed to evaluate the effects of the treatment on the frequency of adenoidectomy in these children.

\section{Materials and methods Subjects}

This trial was approved by the Ethics Committee of the 5th Affiliated Hospital of Sun Yat-sen University and the 1st Affiliated Hospital of Sun Yat-sen University. All children recruited were followed in the outpatient clinics of Otolaryngology and Head Neck Surgery Department of the two hospitals between January 2014 and December 2015, whose primary diagnosis was $\mathrm{AH}$.

Inclusion criteria: 1) prepubescent age (6-8 years), 2 ) symptoms of snoring and nasal obstruction at least for 6 months, 3) AH assessed by radiograph with an adenoidal/ nasopharyngeal ratio $\left.>0.5,{ }^{3} 4\right)$ an obstructive apneahypopnea index score of 2 or more events per hour, ${ }^{16-18}$ and 5) an appointment for an adenoidectomy scheduled after the initial assessment.

Exclusion criteria: 1) they had used intranasal, topical, or systemic steroids or decongestants within the last 6 months, 2) had a history of chronic epistaxis, 3) or immunodeficiency, 4 ) or had active upper respiratory tract infection within 2 weeks after the trial, 5) or could not meet the follow-up, 6) or had a diagnosis of tonsil hypertrophy for a concomitant tonsillectomy, 7) or had a diagnosis of maxillofacial deformity, which causes nasal obstruction.

\section{Study design}

The study consists of two parts (Figure 1). The first part of this trial used a randomized, double-blind design. Eligible children were randomly allocated into two groups (treatment group and control group) after informed consent from the parents was obtained. They received 2 weeks of transnasal nebulization with either budesonide (Pulmicort
Respules $^{\circledR}$ suspension; AstraZeneca plc, London, UK; once daily, $1 \mathrm{mg} / 2 \mathrm{~mL}$ ) or placebo (saline solution, $2 \mathrm{~mL}$ once daily) with a Pari Sinus Nebulizer (PARI GmbH, Starnberg, Germany). Neither the patients and their parents nor the otolaryngologists knew the identity of the medication. The first assessment was made before the treatment, and the second after the 2-week treatment. At the end of the first 2 weeks, all children continued to have a 24-week follow-up for open assessment. The children of the treatment group followed an additional 12-week treatment of intranasal aqueous budesonide spray (Rhinocort, AstraZeneca; $64 \mu \mathrm{g}$ per nostril at bedtime). All the treatments were under the supervision of their parents regularly.

\section{Procedure}

At the beginning of the trial, the children enrolled were initially assessed by medical history, physical examination, parental questionnaire, lateral neck radiograph, skin prick testing for aeroallergens, tympanometry (acoustic immittance measurement), and pure tone audiometry. Subsequent assessments were done at the end of 2, 14, and 26 weeks. All examinations were performed by two otolaryngologists who were blinded to the design of the trial and the treatment assignment for the children throughout the trial. The degree of nasal obstruction was assessed by the reported nasal obstruction index (NOI) using a 4-point scale (1: absent, 2: mild, 3: moderate, 4 : marked). ${ }^{19}$ The degree of snoring and nasal discharge was also ranked on a 4-point scale. OME was identified as either present or not according to the results of the tympanometry and audiometry examination. Every item was recorded in parent-reported questionnaires at the end of 2, 14, and 26 weeks.

The physicians determined medication compliance through both telephone interviews with the families and biweekly measurements of drug administration. Illnesses, and medication prescriptions were also recorded every 2 weeks, and the use of systemic corticosteroids resulted in the removal of children from the trial.

\section{Outcome evaluation}

After the first 2-week trial, the primary outcome was NOI. The children were classified as responders if the reduction of NOI was $\geq 2$ degrees compared with baseline and as nonresponders if the reduction of NOI was $<2$ degrees.

During the 24-week follow-up, other outcome measures included snoring degree, nasal discharge, NOI, occurrence of epistaxis, upper respiratory tract infection, presence or absence of OME, and most importantly, the rate of adenoidectomy in each group. Indications for surgery 


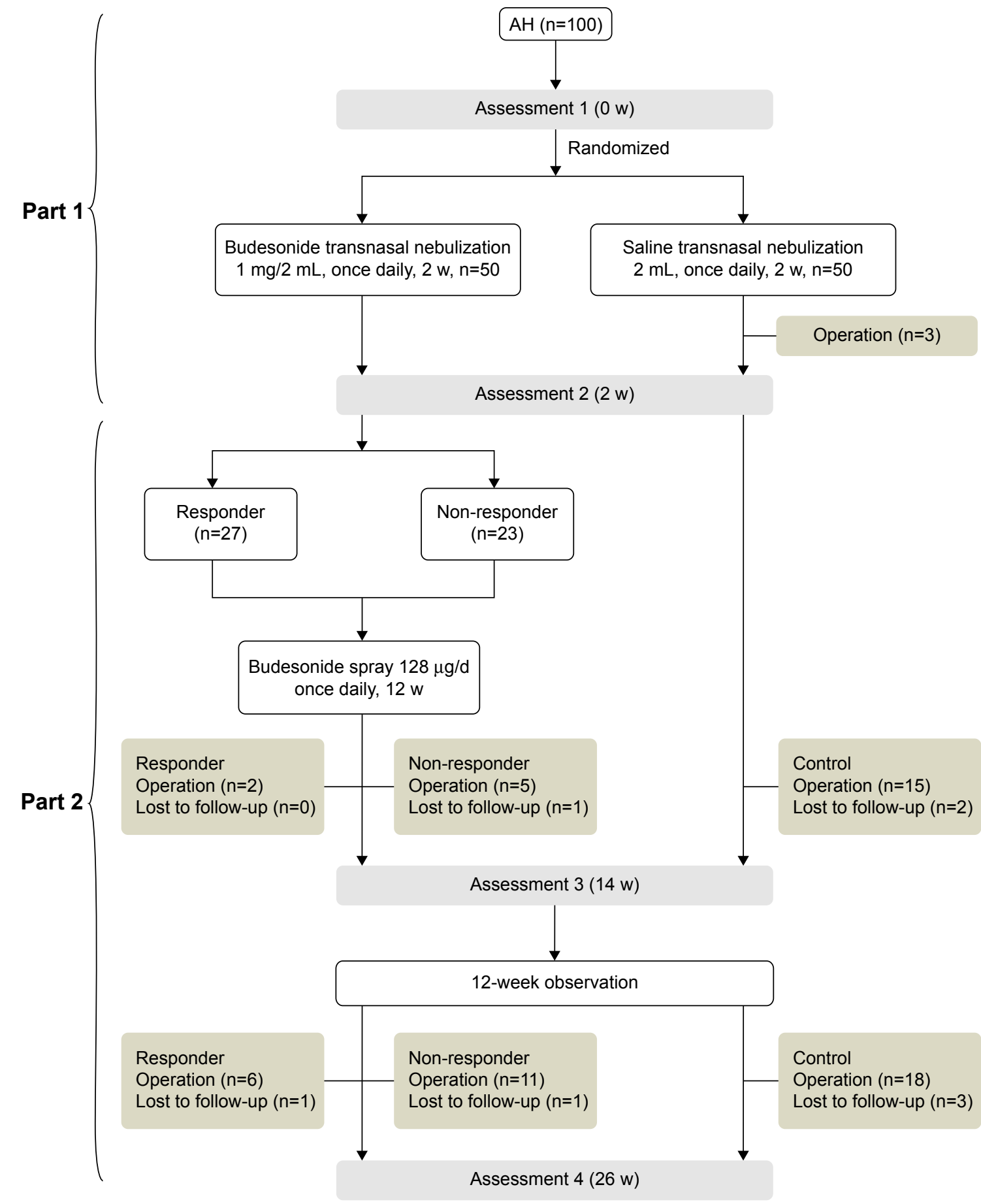

Figure I Flow diagram of this study.

Abbreviations: $\mathrm{AH}$, adenoid hypertrophy; w, weeks.

included snoring degree $>2$ and/or refractory, and non-cured OME. ${ }^{7,18,20,21}$ Children's height was assessed by telephone interviews with the families every 2 weeks.

\section{Statistics}

We determined the sample size using the design of Criscuoli et al. ${ }^{7}$ All our data were processed with SPSS software version 19.0 (IBM Corporation, Armonk, NY, USA), and statistical analyses were conducted using the Wilcoxon signed-rank test, $F$-test, Student's $t$-test, and relative risk with $95 \%$ confidence intervals, as appropriate. A two-sided $P<0.05$ was considered statistically significant.

\section{Results}

A total of 100 children with $\mathrm{AH}$ were recruited into the trial. Three children in the treatment group and five children in 
the control group dropped out because of lost to follow-up. The baseline characteristics are shown in Table 1. The groups were well matched in demographic characteristics, history of disease, symptom severity, and concurrent OME at baseline.

All children with AH completed the initial 2-week double-blind trial. After the initial 2-week trial, three children underwent adenoidectomy due to marked snoring in the control group. Twenty-seven children in the treatment group were defined as responders, and the other 23 were defined as non-responders.

By the end of the trial, the total operation rate significantly decreased in responders compared with non-responders and the control group. The total operative rate between the control group and non-responders showed no significant difference ( $P=0.8047$, Figure 1; Table 2).

After 2 weeks of transnasal nebulization with budesonide, all children in the treatment group showed significant

Table I Characteristics of the children between study groups

\begin{tabular}{|c|c|c|c|}
\hline & \multicolumn{2}{|c|}{ Treatment group } & \multirow{2}{*}{$\begin{array}{l}\text { Control } \\
\text { group } \\
(n=45)\end{array}$} \\
\hline & $\begin{array}{l}\text { Responders* } \\
(\mathrm{n}=26)\end{array}$ & $\begin{array}{l}\text { Non-responders* } \\
(n=2 I)\end{array}$ & \\
\hline $\begin{array}{l}\text { Age (mean, } \\
\text { months [SD]) }\end{array}$ & $83(5.80)$ & $83.74(5.56)$ & $83.16(5.97)$ \\
\hline \multicolumn{4}{|l|}{ Gender } \\
\hline Male & 14 & 9 & 23 \\
\hline Female & 12 & 12 & 22 \\
\hline \multicolumn{4}{|l|}{ Maternal smoking } \\
\hline No & 16 & 13 & 29 \\
\hline Yes & 10 & 8 & 16 \\
\hline \multicolumn{4}{|l|}{ History of atopy } \\
\hline No & 11 & 10 & 19 \\
\hline Yes & 15 & 11 & 26 \\
\hline \multicolumn{4}{|l|}{ Snoring frequency } \\
\hline Persistent & 14 & 10 & 25 \\
\hline Intermittent & 12 & 11 & 20 \\
\hline \multicolumn{4}{|l|}{ Snoring degree } \\
\hline None & 0 & 0 & 0 \\
\hline Mild & 4 & 2 & 9 \\
\hline Moderate & 13 & 15 & 20 \\
\hline Marked & 9 & 5 & 16 \\
\hline \multicolumn{4}{|c|}{ Nasal obstruction index } \\
\hline None & 0 & 0 & 0 \\
\hline Mild & 2 & I & 2 \\
\hline Moderate & II & 9 & 19 \\
\hline Marked & 12 & 11 & 24 \\
\hline $\begin{array}{l}\text { Obstructive sleep } \\
\text { apnea (referred } \\
\text { by the parents) }\end{array}$ & 6 & 4 & 17 \\
\hline \multicolumn{4}{|c|}{ Otitis media with effusion } \\
\hline No & 16 & 13 & 29 \\
\hline Yes & 10 & 8 & 15 \\
\hline
\end{tabular}

Notes: *Children were classified as "responders" if they showed a decrease of $>50 \%$ in their nasal obstruction index after 2 weeks of budesonide. Children who showed a $<50 \%$ decrease were classified as "non-responders".
Table 2 Statistical differences between groups at follow up assessments

\begin{tabular}{|c|c|c|c|c|}
\hline & \multicolumn{3}{|c|}{ Treatment group } & \multirow{2}{*}{$\begin{array}{l}\text { Control } \\
\text { group }\end{array}$} \\
\hline & \multicolumn{2}{|c|}{ Responders } & Non-responders & \\
\hline \multicolumn{5}{|l|}{ Assessment I } \\
\hline Patients & \multicolumn{3}{|l|}{50} & 50 \\
\hline \multicolumn{5}{|l|}{ Assessment 2} \\
\hline Patients & \multicolumn{2}{|l|}{27} & 23 & 50 \\
\hline Operation, n (\%) & \multicolumn{2}{|l|}{0} & 0 & $3(6)$ \\
\hline OME, n (\%) & \multicolumn{2}{|l|}{$10(37.03)$} & $9(39.13)$ & $18(36)$ \\
\hline Epistaxis, n (\%) & \multicolumn{2}{|l|}{0} & 0 & I (2) \\
\hline FURTI & \multicolumn{2}{|l|}{7} & 5 & 13 \\
\hline $\begin{array}{l}\text { Lost to } \\
\text { follow-up }\end{array}$ & \multicolumn{2}{|l|}{0} & 0 & 0 \\
\hline \multicolumn{5}{|l|}{ Assessment 3} \\
\hline Patients & \multicolumn{2}{|l|}{27} & 23 & 47 \\
\hline Operation, n (\%) & $2(7.4 I)$ & ${ }^{\#} P=0.026$ & $5(22.73)$ & $15(33.33)$ \\
\hline OME, n (\%) & \multicolumn{2}{|l|}{$5(18.52)$} & $6(27.27)$ & $13(28.89)$ \\
\hline Epistaxis, n (\%) & \multicolumn{2}{|l|}{$2(7.4 I)$} & I (4.55) & $3(6.67)$ \\
\hline FURTI & \multicolumn{2}{|l|}{46} & 39 & 75 \\
\hline $\begin{array}{l}\text { Lost to } \\
\text { follow-up }\end{array}$ & \multicolumn{2}{|l|}{0} & 1 & 2 \\
\hline \multicolumn{5}{|l|}{ Assessment 4} \\
\hline Patients & \multicolumn{2}{|l|}{25} & 17 & 30 \\
\hline \multirow[t]{2}{*}{ Operation, n (\%) } & \multirow[t]{2}{*}{$6(25)$} & $* P=0.016$ & II (68.8) & $18(66.67)$ \\
\hline & & ${ }^{\# P}=0.007$ & & \\
\hline \multirow[t]{2}{*}{ OME, n (\%) } & \multirow[t]{2}{*}{$3(12.5)$} & $* P=0.025$ & \multirow{2}{*}{7 (43.75) } & \multirow[t]{2}{*}{$10(37.04)$} \\
\hline & & ${ }^{\# P}=0.045$ & & \\
\hline Epistaxis, n (\%) & \multicolumn{2}{|l|}{$3(12.5)$} & $2(12.5)$ & $3(11.11)$ \\
\hline FURTI & \multicolumn{2}{|l|}{36} & 28 & 47 \\
\hline $\begin{array}{l}\text { Lost to } \\
\text { follow-up }\end{array}$ & \multicolumn{2}{|l|}{1} & 1 & 3 \\
\hline $\begin{array}{l}\text { Total operation, } \\
\mathrm{n}(\%)\end{array}$ & $8(30.77)$ & $\begin{array}{l}* P=0.002 \\
\# P=0.001\end{array}$ & $16(76.19)$ & $33(73.33)$ \\
\hline $\begin{array}{l}\text { Total lost to } \\
\text { follow-up }\end{array}$ & 1 & & 2 & 5 \\
\hline
\end{tabular}

Notes: FURTI includes the number of total episodes in the study groups. Statistical differences between responders and non-responders are denoted as $* P<0.05$; \#statistical differences between responders and control group $(P<0.05)$.

Abbreviations: OME, otitis media with effusion; FURTI, frequency of upper respiratory tract infection.

reductions of NOI, nasal discharge degree, and snoring degree compared with the control group $(P<0.001, P<0.001$, and $P=0.001$, respectively). The NOI and nasal discharge degree of responders decreased significantly than non-responders $(P<0.001$ and $P=0.007$, respectively).

At the assessment 3 and assessment 4, the NOI, nasal discharge degree, and snoring degree decreased significantly than those of non-responders and the control group $(P<0.05$, refer to Figure 2 for all precise $P$-values). However, there was no significant difference between those of non-responders and the control group at assessment 4 (Figure 2). A representative case with nasal endoscopic follow-up in responders is shown in Figure 3.

During the 12-week nasal spray with budesonide trial, three children ( 2 responders and 1 non-responder) developed 
A

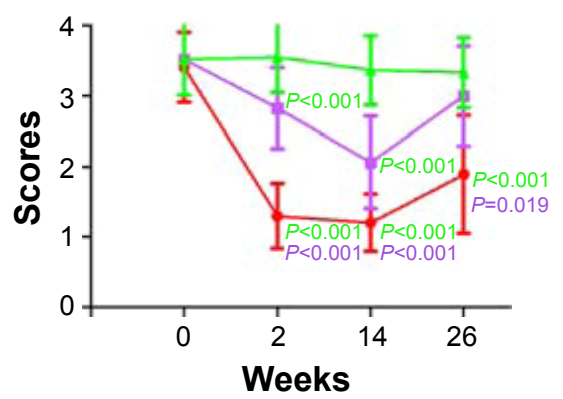

B

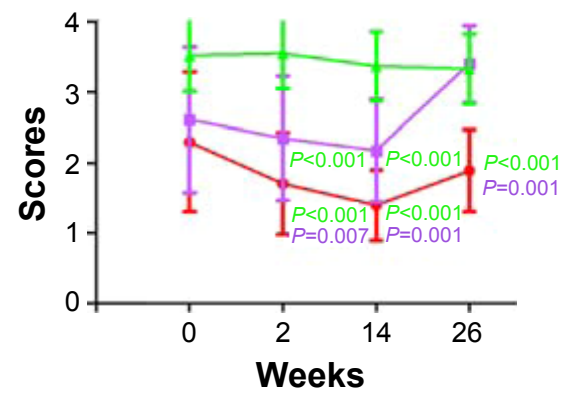

\section{C}

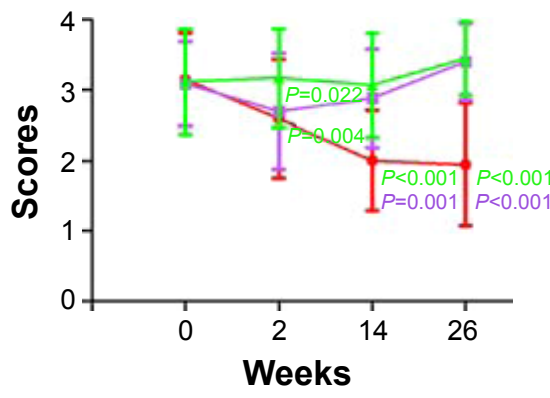

Responders - Non-responders $\neq$ Control group

Figure 2 Clinical improvements between groups, including nasal obstruction index (A), nasal discharge degree (B), and snoring degree (C).

Notes: A P-value in green means the value was compared to the control group. A $P$-value in purple means the value was compared to the non-responder group.

epistaxis, which disappeared within 3 days after correction of spray angle. During the next 12 weeks, 3 responders and 2 non-responders complained of epistaxis, which stopped without intervention. There was no significant difference in the frequency of epistaxis between the treatment group and the control group ( $P>0.05$, Table 2$)$. There was also no significant difference in the frequency of upper respiratory tract infection between the two groups $(P>0.05$, Table 2$)$.
The growth rate also showed no significant differences between the groups $(P>0.05$, Figure 4$)$.

\section{Discussion}

Topical budesonide has been a widely used anti-inflammatory agent in the treatment of asthma, allergic rhinitis, and nasal polyps. ${ }^{10,22,23}$ The pharmacodynamic and pharmacokinetic properties of budesonide inhalation suspension allow for
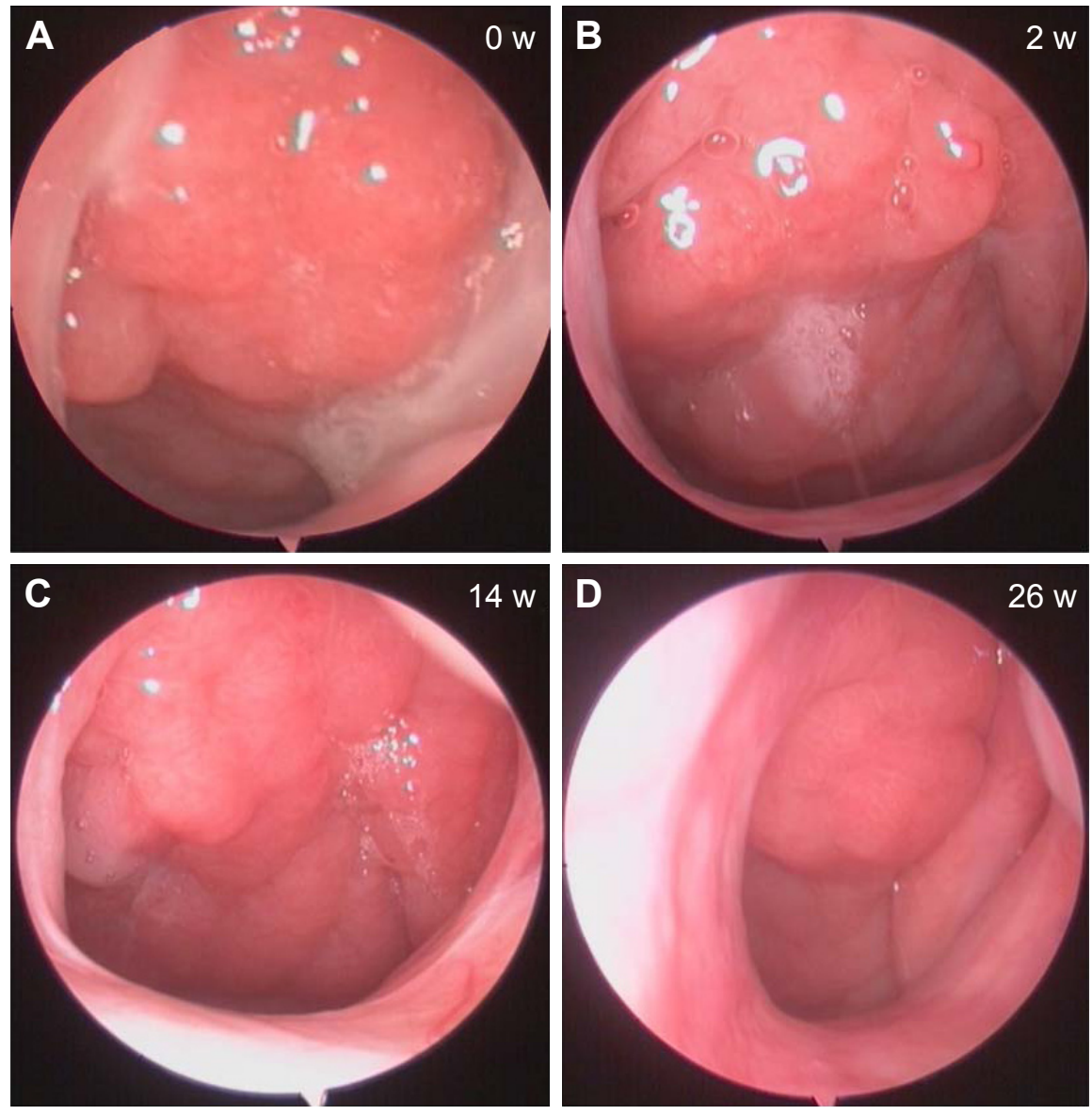

Figure 3 Representative nasal endoscopic follow-ups of a responder at 0 (A), 2 (B), 14 (C), and 26 weeks (D). 


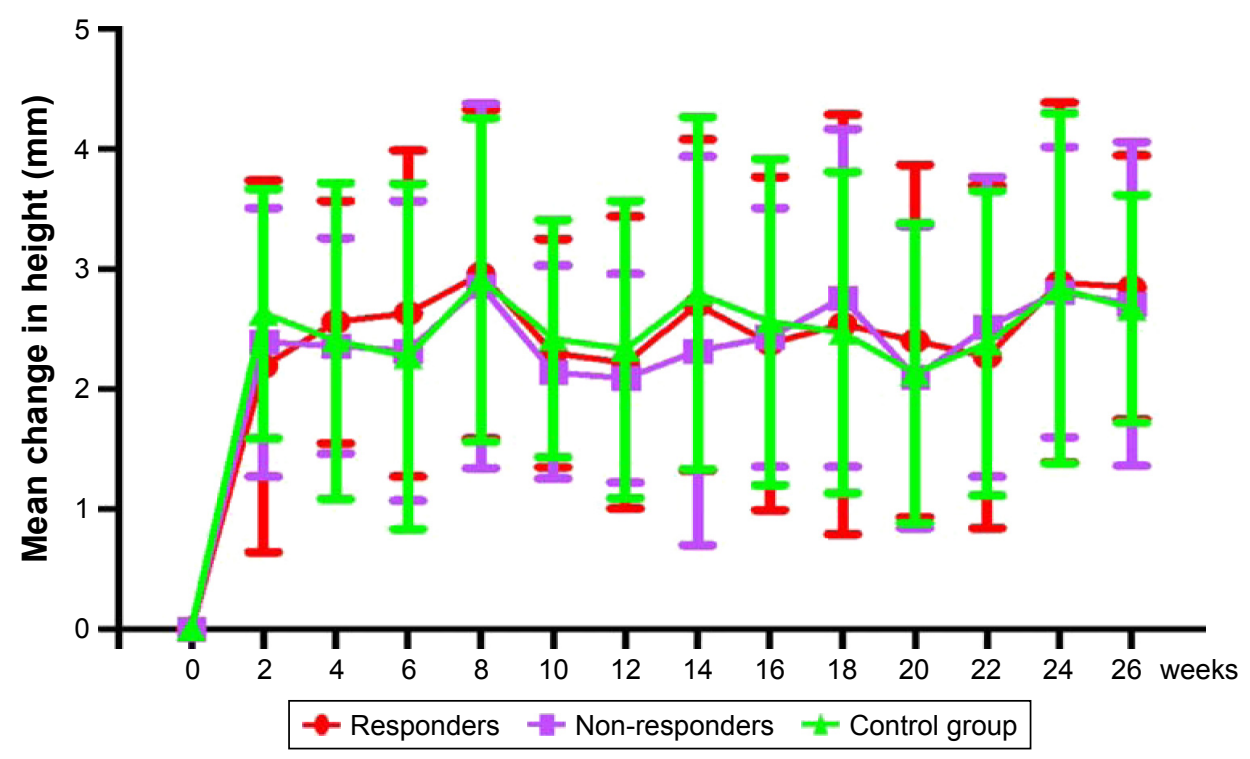

Figure 4 Growth rates of children's height between groups.

potent local anti-inflammatory activity with limited systemic exposure. ${ }^{24-26}$ Studies had focused on the positive effect of budesonide on pediatric snoring due to $\mathrm{AH}$ and chronic inflammation. ${ }^{14,15}$ We have investigated the efficacy underlying the effects of 12-week nasal budesonide treatment in children with AH. Overall, our study indicated that 12-week nasal budesonide treatment led to significantly reduced frequency of adenoidectomy and improvements in all the major symptoms in children after the initial 2-week budesonide administration. Moreover, we have demonstrated that there were no significant differences of major side effects between the treatment group and the control group, showing the safety of 12-week nasal budesonide treatment.

The efficacy of nasal corticosteroids, such as budesonide and beclomethasone, on treating OSA syndrome due to $\mathrm{AH}$ has been investigated previously. ${ }^{7,14,15}$ A pilot study had demonstrated that a 6-week treatment with intranasal budesonide (32 mg per nostril at bedtime) effectively reduced the severity of OSA syndrome and the size of adenoidal hypertrophy, and the effect remained for at least 8 weeks after intermission of treatment. Criscuoli et al had showed that nasal beclomethasone was effective in improving the symptoms of $\mathrm{AH}$ and even reduced the frequency of surgery. ${ }^{7}$ Our findings for the clinical efficacy of 12-week nasal budesonide treatment in children with $\mathrm{AH}$ are in accordance with the findings of these studies. ${ }^{7,14,15}$ However, not all the patients had obvious curative effect from nasal budesonide treatment. Our study showed that there were no significant reductions in the rate of adenoidectomy nor improvements in all the major symptoms between non-responders and the control group 12 weeks after intermission of treatment. Although nasal budesonide treatment to non-responders can result in an improvement in short-term symptoms, the long-term treatment requires further evaluation.

Kheirandish-Gozal et al demonstrated that a variety of corticosteroids could reduce the proliferation rates of lymphoid tissue and enhance cellular apoptosis in vitro, which might lead to shrinkage of adenoid tissue, an effect observed in our study. ${ }^{14}$ A meta-analysis also showed that mometasone nasal spray significantly reduced the size of adenoid compared with the control group. ${ }^{27}$ This mechanism may contribute to the therapeutic efficacy of budesonide in the management of $\mathrm{AH}$ in children, and the responders may be more sensitive to the hormone receptor. Our data show that 12-week nasal budesonide treatment can be an effective manner of avoiding adenoidectomy for some children.

Some other studies have demonstrated the therapeutic safety of budesonide inhalation suspension..$^{10-13,22,28}$ A pilot study showed that treatment with short-term high-dose budesonide (1 $\mathrm{mg}$ of budesonide, transnasal nebulization twice daily for 14 days) neither suppressed the hypothalamicpituitary-adrenal axis nor caused any serious side effects in patients with nasal polyps. ${ }^{10}$ Three separate 12 -week randomized clinical trials ${ }^{11-13}$ had demonstrated that 12 weeks of budesonide nebulization ( $0.25-1 \mathrm{mg}$, once daily) in pediatric patients with asthma neither decreased serum and 24-hour urinary cortisol levels, nor suppressed the hypothalamicpituitary-adrenal axis. Our findings for the safety showed that 12-week nasal budesonide treatment in children with $\mathrm{AH}$ had no significant decrease of the growth rate of children's height. 
However, some recent studies found that the administration of inhaled glucocorticoids for several years in prepubertal children with asthma led to a reduction in adult height. ${ }^{29,30}$ Hence, a longer follow-up period may be needed to confirm our findings. Also, there was no significant difference in the frequency of epistaxis and upper respiratory tract infection between the treatment group and the control group. Collectively, these results suggest that application of 12-week nasal budesonide treatment is safe in children with $\mathrm{AH}$.

\section{Limitations}

Our study has several limitations. First, we only selected cases of persistent/moderate or intermittent/severe snoring, because the indications for adenoidectomy remain controversial. ${ }^{1,7}$ Second, unimproved OME is another indication for surgery due to its complicated prognosis. ${ }^{1,2,21}$ In our trial, three children underwent adenoidectomy for medically incurable OME. If there is no obvious improvement in hearing symptoms, the child should undergo surgery in a timely manner. Third, polysomnography was not performed after treatment because of the reluctance of the children. Fourth, we could not also conduct double-blind trial in part 2 due to the ethical issue of the long-term treatment in a double-blind manner that the children would receive.

\section{Conclusion}

We found that treatment with 12-week nasal budesonide is safe and effective in $\mathrm{AH}$ children. $\mathrm{AH}$ children improved after initial 2-week budesonide therapy can achieve clinical improvements and decreased frequency of adenoidectomy by 12 -week treatment with nasal budesonide.

\section{Acknowledgments}

This study was supported by the Science and Technology Project of Guangdong Province (No 2014A030313101, 2016A020215030, and 2017A020215180) and the Science and Technology Foundation of Zhuhai (PC20081088 and 20161027F060002).

\section{Disclosure}

The authors report no conflicts of interest in this work.

\section{References}

1. Kaditis AG, Alonso AM, Boudewyns A, et al. Obstructive sleep disordered breathing in 2- to 18-year-old children: diagnosis and management. Eur Respir J. 2016;47:69-94.

2. Baugh RF, Archer SM, Mitchell RB, et al. Clinical practice guideline: tonsillectomy in children. Otolaryngol Head Neck Surg. 2011;144: S1-S30.
3. Brodsky L. Modern assessment of tonsils and adenoids. Pediatr Clin North Am. 1989;36:1551-1569.

4. Garetz SL, Mitchell RB, Parker PD, et al. Quality of life and obstructive sleep apnea symptoms after pediatric adenotonsillectomy. Pediatrics. 2015;135:e477-e486.

5. Zojaji R, Mirzadeh M, Mazloum FBM, Khorashadizadeh M, Sabeti HR. The effect of adenotonsillectomy on children's quality of life. Iran $J$ Otorhinolaryngol. 2014;26:199-205.

6. Cummings CW, Flint PW, Harker LA, et al. Otolaryngology Head and Neck Surgery. San Francisco: Mosby; 2005.

7. Criscuoli G, D'Amora S, Ripa G, et al. Frequency of surgery among children who have adenotonsillar hypertrophy and improve after treatment with nasal beclomethasone. Pediatrics. 2003;111:e236-e238.

8. Demain JG, Goetz DW. Pediatric adenoidal hypertrophy and nasal airway obstruction: reduction with aqueous nasal beclomethasone. Pediatrics. 1995;95:355-364.

9. Lepcha A, Kurien M, Job A, Jeyaseelan L, Thomas K. Chronic adenoid hypertrophy in children - is steroid nasal spray beneficial? Indian $J$ Otolaryngol Head Neck Surg. 2002;54:280-284.

10. Wang C, Lou H, Wang X, et al. Effect of budesonide transnasal nebulization in patients with eosinophilic chronic rhinosinusitis with nasal polyps. J Allergy Clin Immunol. 2015;135:922-929.

11. Scott MB, Ellis MH, Cruz-Rivera M, Fitzpatrick S, Smith JA. Oncedaily budesonide inhalation suspension in infants and children $<4$ and $\geq 4$ years of age with persistent asthma. Ann Allergy Asthma Immunol. 2001;87:488-495.

12. Baker JW, Mellon M, Wald J, Welch M, Cruz-Rivera M, WaltonBowen K. A multiple-dosing, placebo-controlled study of budesonide inhalation suspension given once or twice daily for treatment of persistent asthma in young children and infants. Pediatrics. 1999;103: 414-421.

13. Kemp JP, Skoner DP, Szefler SJ, Walton-Bowen K, Cruz-Rivera M, Smith JA. Once-daily budesonide inhalation suspension for the treatment of persistent asthma in infants and young children. Ann Allergy Asthma Immunol. 1999;83:231-239.

14. Kheirandish-Gozal L, Serpero LD, Dayyat E, et al. Corticosteroids suppress in vitro tonsillar proliferation in children with obstructive sleep apnoea. Eur Respir J. 2009;33:1077-1084.

15. Kheirandish-Gozal L, Gozal D. Intranasal budesonide treatment for children with mild obstructive sleep apnea syndrome. Pediatrics. 2008; 122:e149-e155.

16. Uliel S, Tauman R, Greenfeld M, Sivan Y. Normal polysomnographic respiratory values in children and adolescents. Chest. 2004;125: 872-878.

17. Witmans MB, Keens TG, Davidson WS, Marcus CL. Obstructive hypopneas in children and adolescents: normal values. Am J Respir Crit Care Med. 2003;168:1540.

18. Chervin RD, Ellenberg SS, Hou X, et al. Prognosis for spontaneous resolution of OSA in children. Chest. 2015;148:1204-1213.

19. Paradise JL, Bernard BS, Colborn DK, Janosky JE. Assessment of adenoidal obstruction in children: clinical signs versus roentgenographic findings. Pediatrics. 1998;101:979-986.

20. Maw AR, Parker A. Surgery of the tonsils and adenoids in relation to secretory otitis media in children. Acta Otolaryngol Suppl. 1988;454: 202-207.

21. van den Aardweg MT, Schilder AG, Herkert E, Boonacker CW, Rovers MM. Adenoidectomy for otitis media in children [review]. Cochrane Database Syst Rev. 2010:D7810.

22. Loke YK, Blanco P, Thavarajah M, Wilson AM. Impact of inhaled corticosteroids on growth in children with asthma: systematic review and meta-analysis. PLoS One. 2015;10:e133428.

23. Samolinski B, Nowicka A, Wojas O, Lipiec A, Krzych-Falta E, Tomaszewska A. Intranasal glucocorticosteroids - not only in allergic rhinitis in the 40th anniversary of intranasal glucocorticosteroids introduction. Otolaryngol Pol. 2014;68:51-64.

24. Rizzo MC, Sole D. Inhaled corticosteroids in the treatment of respiratory allergy: safety vs. efficacy. J Pediatr (Rio J). 2006;82:S198-S205. 
25. Szefler SJ. Pharmacodynamics and pharmacokinetics of budesonide: a new nebulized corticosteroid. J Allergy Clin Immunol. 1999;104: $175-183$.

26. O'Byrne PM, Pedersen S. Measuring efficacy and safety of different inhaled corticosteroid preparations. J Allergy Clin Immunol. 1998;102: 879-886.

27. Chohan A, Lal A, Chohan K, Chakravarti A, Gomber S. Systematic review and meta-analysis of randomized controlled trials on the role of mometasone in adenoid hypertrophy in children. Int J Pediatr Otorhinolaryngol. 2015;79:1599-1608.
28. Reddel HK, Busse WW, Pedersen S, et al. Should recommendations about starting inhaled corticosteroid treatment for mild asthma be based on symptom frequency: a post-hoc efficacy analysis of the START study. Lancet. 2016;389(10065):157-166.

29. Nissly T, Prasad S. This asthma treatment has a lasting side effect in children. J Fam Pract. 2013;62:500-502.

30. Kelly HW, Sternberg AL, Lescher R, et al. Effect of inhaled glucocorticoids in childhood on adult height. $N$ Engl J Med. 2012;367: 904-912.

\section{Publish your work in this journal}

Therapeutics and Clinical Risk Management is an international, peerreviewed journal of clinical therapeutics and risk management, focusing on concise rapid reporting of clinical studies in all therapeutic areas, outcomes, safety, and programs for the effective, safe, and sustained use of medicines. This journal is indexed on PubMed Central, CAS,
EMBase, Scopus and the Elsevier Bibliographic databases. The manuscript management system is completely online and includes a very quick and fair peer-review system, which is all easy to use. Visit http://www.dovepress.com/testimonials.php to read real quotes from published authors.

Submit your manuscript here: http://www.dovepress.com/therapeutics-and-clinical-risk-management-journal 